\title{
FORMULATION AND EVALUATION OF ACECLOFENAC MUCOADHESIVE MICROSPHERES FOR ORAL CONTROLLED DRUG DELIVERY
}

\author{
SAROJA SP, PREETHI SUDHEER* \\ Department of Pharmaceutics, Krupanidhi College of Pharmacy, Chikkabellandur, Varthur Hobli, Bengaluru, Karnataka, India. \\ Email: preetisudheer@gmail.com
}

Received: 24 April 2019, Revised and Accepted: 19 July 2019

\begin{abstract}
Objective: Drug delivery is a broad field of research on the development of novel materials or carrier systems for effective therapeutic delivery of drugs. The main purpose of delivering the drugs to mucosal membrane is lengthening of the residence time at site of drug delivery, followed by sustained release of the drug after the deposition. Aceclofenac is a non-steroidal anti-inflammatory drug that has a half-life of 4 h. The frequent administration of the drug irritates the gastric mucosa when it is given in conventional dosage forms.
\end{abstract}

Method: Hence in this study, a mucoadhesive microsphere of biopolymer chitosan was formulated with an aim to enhance the efficacy of the drug. The microsphere of aceclofenac was prepared by o/w/o emulsification cross linking method.

Results: Various ratios of drug: polymer were studied, and it was found that microspheres with 1:4 ratio was the superior in terms drug content of $87.23 \pm 0.56 \%$.and entrapment efficiency of $85.8 \pm 0.16 \%$.The in vitro drug release profiles indicated a maximum drug release of $89.55 \pm 0.62 \%$ in $12 \mathrm{~h}$. The extent of mucoadhesion and ex- vivo permeation of the drug was studied using porcine intestinal mucosal sample. The microspheres were retained on the intestinal mucosa up to $12 \mathrm{~h}$. The surface of the selected microsphere formulation was observed to be uneven during surface electron microscopic studies. Infrared spectroscopy and differential scanning calorimetry studies indicated that there was no major interaction between the drug and the polymer used.

Conclusion: Therefore, the studies demonstrate that mucoadhesive microspheres could be an appropriate dosage to improve the gastric retention and efficacy of aceclofenac.

Keywords: Aceclofenac, Mucoadhesion, Microspheres, Permeation, Controlled delivery, Entrapment efficiency.

(C) 2019 The Authors. Published by Innovare Academic Sciences Pvt Ltd. This is an open access article under the CC BY license (http://creativecommons. org/licenses/by/4. 0/) DOI: http://dx.doi.org/10.22159/ajpcr.2019.v12i9.33736

\section{INTRODUCTION}

Controlled drug delivery systems (CDDS) are acquiring a significant position in the area of pharmaceutical research development sector [1]. CDDS offer many advantages such as constant drug level at the site of action, prevention of peak-valley fluctuation, reduction in the dose of drug, reduced dosage frequency, avoidance of side effects and improved patient compliance [1,2].

Mucoadhesive drug delivery systems has the potential to optimize both localized and systemic drug delivery by retaining a dosage form at the site of action and by intimate contact with the absorption site respectively [3] The advantage of using microspheres as oral mucoadhesive drug delivery system is that they can be trapped in the reductus of the stomach, and stay there longer. Besides, when poorly soluble drugs are loaded in the microspheres, they are either adsorbed at the surface of the microspheres or highly dispersed in the inner part of the microspheres which helps to enhance the solubility of poorly soluble drugs, results in reduction of drug dose, consequent minimization of side effects and improved bioavailability $[4,5]$.

Aceclofenac is a non-steroidal anti-inflammatory drug, a potent inhibitor of the enzyme cyclo-oxygenase (COX), which is involved in the production of prostaglandins. Oral administration of aceclofenac is associated with inherent gastrointestinal side effects such as diarrhoea, stomach pain, vomiting etc. The mean plasma elimination half-life of the drug is around $4 \mathrm{~h}$. Therefore frequent administration is required to maintain therapeutic plasma levels. To overcome inherent drawbacks associated with conventional oral dosage forms of aceclofenac, an attempt was made to develop an alternative drug delivery system in the form of mucoadhesive microspheres, which may release the drug over a prolonged period of time in a controlled manner is expected to reduce the gastrointestinal side effects to an extent. Moreover the microspheres are expected to retain on the mucus membrane due to its adhesive nature, which may contribute an additional therapeutic potential $[6,7]$.

\section{MATERIALS AND METHODS}

Materials

Aceclofenac was obtained from Micro Labs Bangalore, Chitosan was obtained from CIFL, Cochin, Kerala. Other solvents and reagents of laboratory grade are used.

\section{Methods}

Preparation of microspheres by o/w/o emulsification cross-linking method

Aceclofenac microspheres were prepared by double emulsification technique. A $1 \% \mathrm{w} / \mathrm{v}$ solution of chitosan was prepared in $1 \%$ aqueous acetic acid. Aceclofenac is dissolved in $10 \mathrm{ml}$ of (1:1) acetone and methanol. The drug solution was added to the polymer solution under mechanical stirring and solution was further stirred to $2 \mathrm{~h}$. The drug-polymer solution was added to $100 \mathrm{ml}$ of light liquid paraffin containing $0.5 \mathrm{~g}$ of span 60 under mechanical stirring at $600 \mathrm{rpm}$ and stirring was continued for $3 \mathrm{~h}$. To the above, glutaraldehyde solution $25 \% \mathrm{v} / \mathrm{v}$ was added, stirring was continued for overnight. After centrifugation, the microspheres were collected, washed with $5 \times 10 \mathrm{ml}$ of petroleum ether, air dried and stored in desiccators at room temperature [8-10]. Five different formulations with drug: polymer ratios $(1: 0.5,1: 1,1: 1.5,1: 2$, and $1: 2.5)$ were prepared and coded as F1 to F5 as given in Table 1 . 
Table 1: Formulation of microsphers

\begin{tabular}{lllllll}
\hline \multirow{2}{*}{ S. No. } & Ingredients & \multicolumn{6}{l}{ Formulation code } \\
\cline { 3 - 7 } & & F1 & F2 & F3 & F4 & F5 \\
\hline 1 & Aceclofenac (mg) & 100 & 100 & 100 & 100 & 100 \\
2 & Chitosan (mg) & 50 & 100 & 150 & 200 & 250 \\
3 & Liquid paraffin (ml) & 100 & 100 & 100 & 100 & 100 \\
4 & Span 60 (mg) & 0.5 & 0.5 & 0.5 & 0.5 & 0.5 \\
5 & Glutaraldehyde (ml) & 3 & 3 & 3 & 3 & 3 \\
6 & Petroleum Ether (ml) & 100 & 100 & 100 & 100 & 100 \\
7 & Acetone: methanol & 10 & 10 & 10 & 10 & 10 \\
& $(1: 1)(m l)$ & & & & & \\
\hline
\end{tabular}

\section{Evaluation of microspheres}

Drug polymer interaction by fourier transformation infrared Spectroscopy (FTIR)

Infrared spectra of pure drug, selected formulation were taken by potassium bromide $(\mathrm{KBr})$ pellet technique. The IR spectra was recorded in the range of $4000-400 \mathrm{~cm}^{-1}$ using FTIR spectrophotometer Model (IR Affinity-1Shimadzu Corporation, Japan [11].

\section{Differential scanning calorimetry (DSC)}

The physical state of aceclofenac in the microspheres was analyzed by differential scanning calorimeter (Mettler-Toledo star 822e system, Switzerland). The thermograms of the aceclofenac and microspheres were obtained at a scanning rate of $10^{\circ} \mathrm{C} / \mathrm{min}$ conducted over a temperature range of $50-350^{\circ} \mathrm{C}$, respectively [11]

\section{Drug content}

About $25 \mathrm{mg}$ of drug equivalent microspheres were crushed in a mortar using pestle. This was dissolved in $50 \mathrm{ml}$ of methanol. The solution was shaken for 2 to $3 \mathrm{~h}$ in a mechanical stirrer. The solution was filtered through Whatman filter paper, analyzed spectrophotometrically for the drug content after sufficient dilution with PBS pH 6.8 [12].

\section{Drug entrapment efficiency}

To determine the entrapment efficiency, microspheres equivalent to $25 \mathrm{mg}$ of drug was washed with $10 \mathrm{ml}$ of methanol to remove the surface associated drug. The microspheres were then digested in $10 \mathrm{ml}$ of solvent for $12 \mathrm{~h}$ at room temperature to release the entrapped drug. Drug content was determined spectrophotometrically at $274 \mathrm{~nm}$ [12].

$$
\% \text { Entrapment efficiency }=\frac{W_{0}-W}{W_{0}} \times 100
$$

Where, Wo=Total drug content, $\mathrm{W}=$ Free drug content

\section{Particle size analysis}

Particle size analysis was carried out by optical microscopy. About 100 microspheres were selected randomly and their size was determined using optical microscope fitted with a standard micrometer scale. And also particle size characterization was carried out by photon correlation spectroscopy (PCS) using Malvern Zetasizer 2000 [11].

\section{Scanning electron microscopy (SEM)}

Scanning electron microscopy has been used to determine particle size distribution, surface morphology etc. Scanning electron microscope model JEOL JSMT-330(Japan) was used to for the study. The dry aceclofenac microspheres were placed on an electron microscope brass stub and coated within anion sputter and studied for the surface properties [11].

\section{In-vitro release studies}

Release of the drug from the loaded microspheres was studied by using USP type I dissolution test apparatus (basket). Microspheres equivalent to $100 \mathrm{mg}$ of aceclofenac were taken in the study. PBS pH $6.8(900 \mathrm{ml})$ was used as dissolution medium and the study was continued up to $12 \mathrm{~h}$.
Stirring rate was maintained at $50 \mathrm{rpm}$ at temperature of $37^{\circ} \mathrm{C} \pm 0.5^{\circ} \mathrm{C}$. Aliquots of sample were withdrawn at regular time intervals, $\mathrm{s}$ filtered through Whatman filter paper, and assayed spectrophotometrically at $274 \mathrm{~nm}[12]$.

\section{Kinetics of drug release}

In order to investigate the mechanism of drug release from microspheres of different ratios, the release data obtained from dissolution studies was fitted to various kinetic equations [12].

\section{Degree of swelling}

The microspheres were allowed to swell in PBS pH 6.8.About $100 \mathrm{mg}$ of microspheres were added to little excess of PBS pH 6.8 for $24 \mathrm{~h}$ and filtered. And excess of water is removed by using blotting paper and re-weighed. The percentage degree of swelling was calculated using the following formula: $\frac{w s-w o}{w o} \times 100$, Wo is the weight of microspheres before swelling; $W s$ is the weight of microspheres after swelling $[13,14]$.

\section{Ex-vivo mucoadhesion time}

A piece of porcine gastrointestinal mucosa was tied onto a glass slide. About $50 \mathrm{mg}$ microspheres was placed on tissue specimen, which was previously wetted with PBS $\mathrm{pH}$ 6.8. This entire assembly was in turn attached to basket rack assembly of USP tablet disintegrating test apparatus. The disintegrating test apparatus was operated such that tissue specimen was given regular up and down movements in a beaker containing $900 \mathrm{ml}$ of PBS pH 6.8 which was maintained at $37^{\circ} \mathrm{C}$. The time taken for the microspheres to completely detach from tissue was noted [15].

\section{Ex-vivo permeation study}

A piece of porcine gastrointestinal mucosa was placed between donor and receptor compartment of Franz diffusion cell in such a way that mucosal side faces the donor compartment. The microspheres were placed on mucosal side of membrane which was wetted with $1 \mathrm{ml}$ of PBS pH 6.8. The receptor compartment was filled with $50 \mathrm{ml}$ of (PBS) $\mathrm{pH}$ 7.4, which was magnetically stirred. Aliquots from receptor compartment were collected at different time intervals and drug content was determined at $274 \mathrm{~nm}[16,17]$.

\section{Stability study}

The stability study was carried out for selected formulation as per ICH guidelines. Various ICH storage conditions are available which are as $25^{\circ} \mathrm{C} \pm 2^{\circ} \mathrm{C}(60 \% \pm 5 \% \mathrm{RH}), 30^{\circ} \mathrm{C} \pm 2^{\circ} \mathrm{C}(65 \% \pm 5 \% \mathrm{RH})$ and $40^{\circ} \mathrm{C} \pm 2^{\circ} \mathrm{C}$ (75\% $\pm 5 \% \mathrm{RH}$ ). The microsphere formula (F4) was placed in screw capped glass container and stored at the above mentioned storage conditions for a period of $60 \mathrm{~d}$. The samples were checked for the physical appearance and the drug content at interval of $30 \mathrm{~d}$ [16].

\section{RESULTS AND DISCUSSION}

\section{Drug polymer interaction study}

One of the objective of any preformulation study is to check the compatibility of the drug with the exicipients used. In this study, the drug polymer interaction is checked by IR spectroscopic method using potassium bromide method. The principal peaks exhibited in the FTIR spectra of the pure aceclofenac were $3317 \mathrm{~cm}^{-1}$ for aromatic $\mathrm{C}=\mathrm{H}$ stretching, $1649 \mathrm{~cm}^{-1}$ for $\mathrm{NH}$ bending, $1683 \mathrm{~cm}^{-1} \mathrm{C}=\mathrm{C}$ aliphatic stretching, broad peaks $3000 \mathrm{~cm}^{-1}$ and $2850 \mathrm{~cm}^{-1}$ due to $\mathrm{C}=\mathrm{C}$ aromatic stretching, $3070 \mathrm{~cm}^{-1}$ for aromatic $\mathrm{C}-\mathrm{H}$ stretching etc. All the above mentioned peaks were expressed in the physical mixture of chitosan and aceclofenac. The appearance of the peaks in the IR spectra of the physical mixture as well as the selected formula (F4) suggests no considerable interaction existed between drug and polymer used in the formulation as given in the Fig. 1.

\section{DSC studies}

In order to confirm the compatibility of aceclofenac with polymers, DSC analysis was carried out. DSC helps to study the behavioral changes of the drug and polymer as a function of temperature. DSC thermogram of aceclofenac showed a sharp endothermic peak at $156.15^{\circ} \mathrm{C}$. In the thermogram of the microspheres as given in Fig. 2, an endothermic 


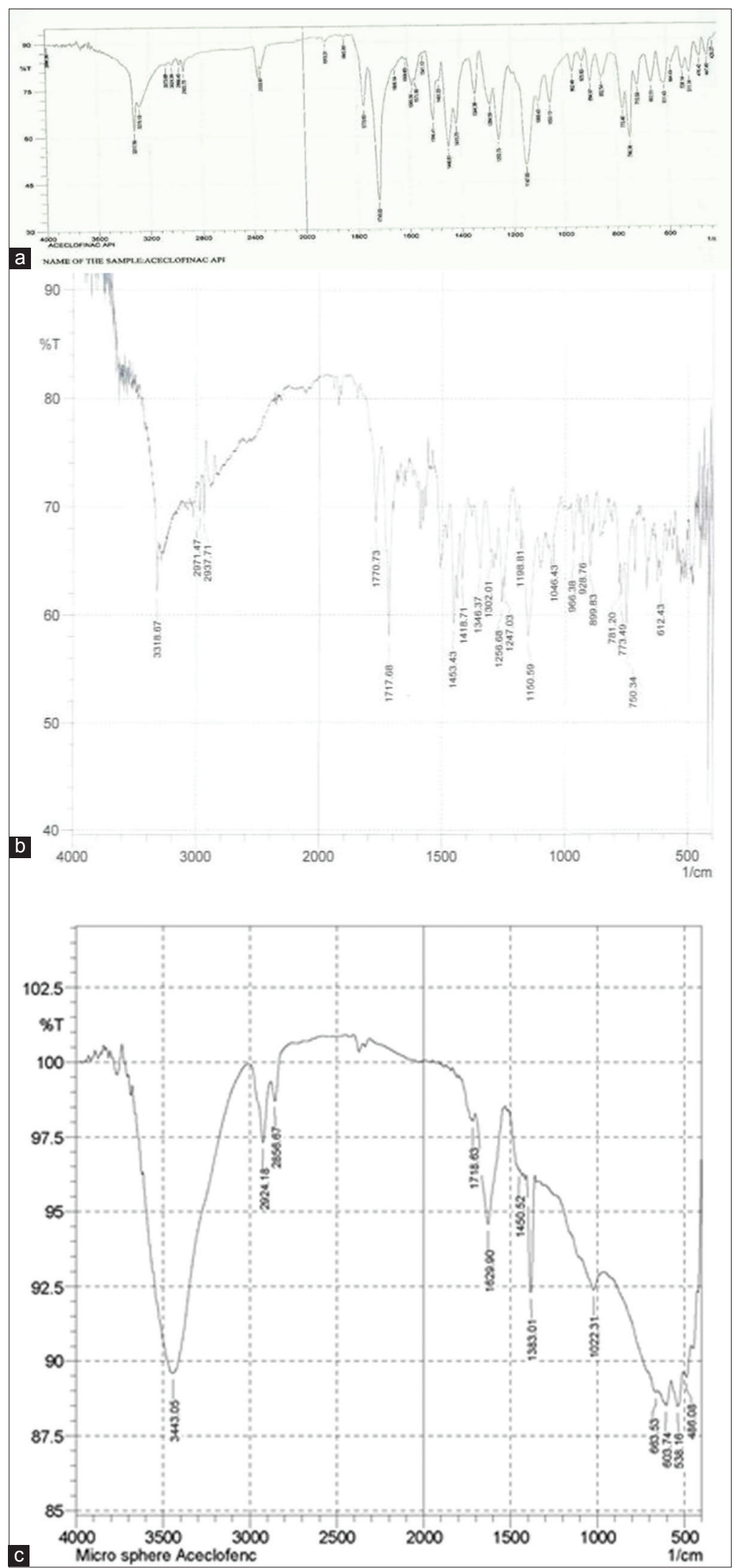

Fig. 1: FTIR Spectrum of a) Pure drug, b) Physical mixture c) aceclofenac Microspheres

peak was observed at $152^{\circ} \mathrm{C}$, Broadening of the thermogram might have resulted from phase transition such as glass transition.At glass transition, the amorphous chitosan might have converted from brittle glass form to a rubbery flexible form. However, existence of the endothermic peak at $152^{\circ} \mathrm{C}$ is a clear indication of the compatibility of the drug in formulation in presence of all excipients. 


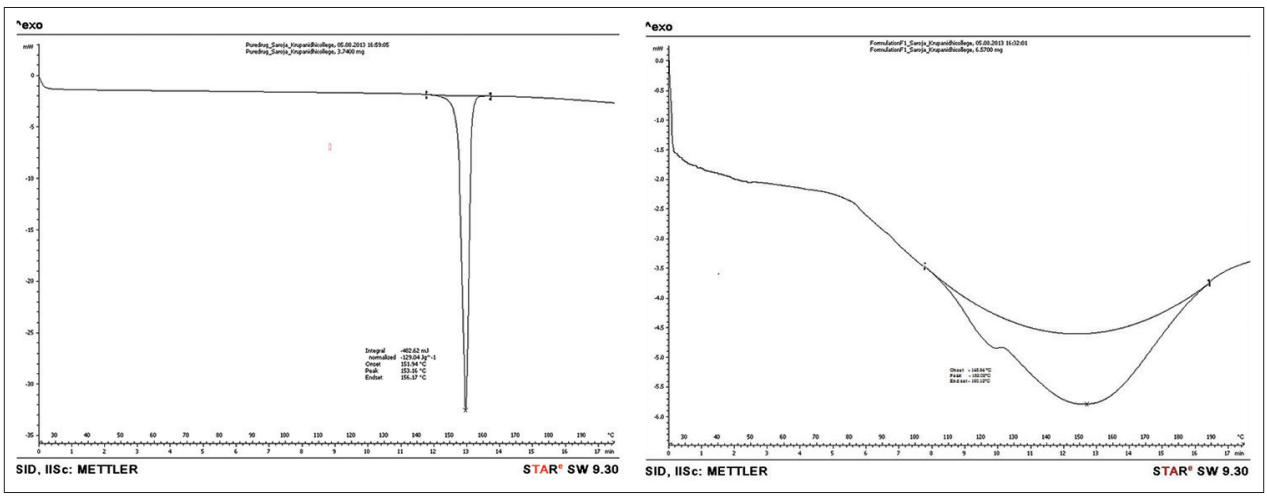

Fig. 2: DSC thermogram of aceclofenac, Formulation F4

Table 2: kinetics of drug release

\begin{tabular}{|c|c|c|c|c|c|}
\hline \multirow{3}{*}{$\begin{array}{l}\text { Formulation } \\
\text { code }\end{array}$} & Zero & First & Higuchi & \multirow{2}{*}{$\begin{array}{l}\text { Peppas } \\
\text { plot }\end{array}$} & \multirow[t]{2}{*}{ 'n' value } \\
\hline & Order & Order & Matrix & & \\
\hline & \multicolumn{5}{|l|}{$\mathbf{r}^{2}$ value } \\
\hline F1 & 0.9807 & 0.9794 & 0.9815 & 0.9942 & 0.63 \\
\hline F2 & 0.9747 & 0.9734 & 0.9810 & 0.9919 & 0.58 \\
\hline F3 & 0.9705 & 0.9527 & 0.9851 & 0.9827 & 0.56 \\
\hline F4 & 0.9724 & 0.9672 & 0.9829 & 0.9864 & 0.56 \\
\hline F5 & 0.9630 & 0.9622 & 0.9897 & 0.9875 & 0.54 \\
\hline
\end{tabular}

\section{Evaluation of microspheres}

The microspheres were prepared on the basis of preliminary investigation on blank microspheres, without using drug. Formulation parameters such as concentration of surfactant and volume of the solvent in the formula and processing parameters stirring speed and time was selected on the basis of preliminary studies. Total five formulations were prepared by keeping the quantity of the drug as $100 \mathrm{mg}$ which is equivalent to the single dose of aceclofenac and the drug: polymer ratios to 1:0.5-1:2.5. The percentage drug content of the formulations was in the range of $68.12 \pm 0.12$ to $87.23 \pm 0.56 \%$ and entrapment efficiency was $48.4 \pm 0.29$ to $89.8 \pm 0.16 \%$. The drug content was seen that as the drug: polymer ratio increased, the drug content and the entrapment efficiency increased up to the ratio 1:2 and further there was considerable decrease in the drug content and entrapment efficiency, possibly due to the lack of emulsification efficiency of the dispersed system at the concentration of surfactant used. As far as the swelling behavior is concerned, chitosan undergoes a moderate and sustained swelling and takes up around $183 \%$ of is weight. Swelling index of the formulations in PBS pH 6.8 indicated that a proportionate percentage swelling was observed as the concentration of polymer increased. This swelling nature of the polymer would have accounted for slow diffusion controlled release of the drug during in vitro release studies. The extent of mucoadhesion was carried out using modified USP tablet disintegration test apparatus assembly on a porcine intestinal tissue sample. Chitosan is a cationic polysacccahride, being primary amino and hydroxyl group in each unit except for acetylated group. When they get protonated, they bear a positive charge, which facilitates electrostatic interactions negatively charges molecules. Due to the higher surface area to the volume of the microspheres, the interactions are found to be maximum, therefore extent of mucoadhesion on porcine mucosa was found to be in the range 6-12 $\mathrm{h}$. The mucoadhesion property was found to be increasing as the drug to polymer ratio increased. Also uneven and rough surface property of the microspheres would have added to the increased time of mucoadhesion (Fig. 3).

The microsphere formulations obtained were checked for physical appearance and free flowing nature. All the formulations were found have particles which are discrete in nature and free flowing.

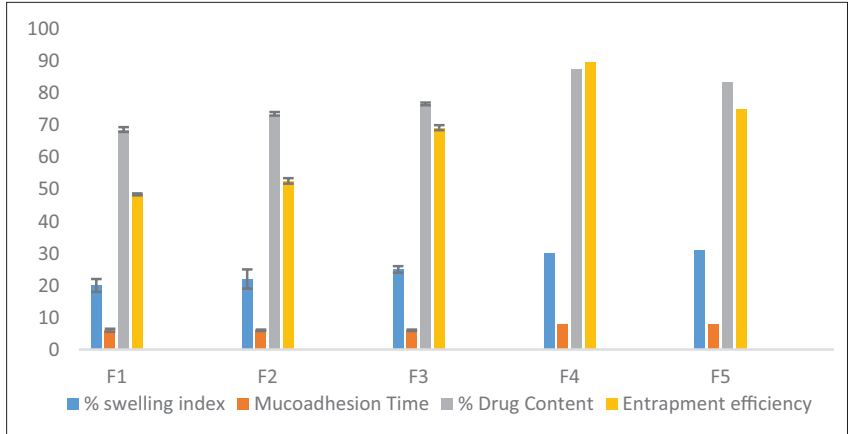

Fig. 3: Evaluation of microspheres

The frequency of distribution was maximum in the range of $10 \mu \mathrm{m}$ $100 \mu \mathrm{m}$. The formula which was superior in terms of drug content and entrapment efficiency was further analyzed for its size distribution pattern by master sizer. Particle size distribution by master sizer indicates the average particle of $47.18 \mu \mathrm{m}$. The poly dispersibility index of 1.33 suggests that maximum particles were near the size range of mean particle size, with minimum deviation. The results are given in Fig. 4-6.

\section{Surface morphological studies}

Surface morphology of selected formula F4 by scanning electron microscope shows that the formulations were spherical with uneven surfaces as shown in the Fig. 7. The roughness of the surface is a contributing factor for good mucoadhesive properties of microspheres. The mechanical theory of mucoadhesion suggests that the mucoadhesion is due to the filling of irregularities by a mucoadhesive liquid. Therefore the roughness can increase the interfacial area available for interactions, thereby dissipates the surface free energy. So this surface free energy reduction propose to contribute a greater extent to mucoadheion also.

\section{In vitro release studies}

All the five formulations were studied for the release profile of the drug from microspheres in PBS pH 6.8. An initial burst release of drug was observed in the first 30 min followed by a prolonged release. This burst release may be due to the surface unentrapped drug which has the advantage of producing an immediate therapeutic effect.

The in vitro release profile of the drug from microspheres shows an increase the drug release pattern from F1 to F4. And for F5, the maximum rate of drug release was found by $85.02 \pm 0.26 \%$ in a $12 \mathrm{~h}$. An increase in polymer concentration usually retards the drug release, as the drug should pass through long diffusion path lengths. However from $\mathrm{F} 4$, the drug release was found to be maximum compared to all other formulations. The higher entrapment efficiency of F4 might have resulted in a higher concentration gradient resulting a higher percentage of drug release. The results are showed in Fig. 8. 
Table 3: Stability studies of formulation F4

\begin{tabular}{|c|c|c|c|c|c|c|}
\hline \multirow{2}{*}{\begin{tabular}{|l}
$\begin{array}{l}\text { Storage } \\
\text { condition }\end{array}$ \\
No. of Days
\end{tabular}} & \multicolumn{2}{|c|}{$25^{\circ} \mathrm{C} \pm 2^{\circ} \mathrm{C} / 60 \% \pm 5 \% \mathrm{RH}$} & \multicolumn{2}{|c|}{$30^{\circ} \mathrm{C} \pm 2^{\circ} \mathrm{C} / 65 \% \pm 5 \% \mathrm{RH}$} & \multicolumn{2}{|c|}{$40^{\circ} \mathrm{C} \pm 2^{\circ} \mathrm{C} / 75 \% \pm 5 \% \mathrm{RH}$} \\
\hline & $\begin{array}{l}\text { Physical } \\
\text { Appearance }\end{array}$ & $\begin{array}{l}\% \text { Drug } \\
\text { Entrapment }\end{array}$ & $\begin{array}{l}\text { Physical } \\
\text { Appearance }\end{array}$ & $\begin{array}{l}\% \text { Drug } \\
\text { Entrapment }\end{array}$ & $\begin{array}{l}\text { Physical } \\
\text { Appearance }\end{array}$ & $\begin{array}{l}\% \text { Drug } \\
\text { Entrapment }\end{array}$ \\
\hline 0 & Yellow powder & $85.8 \pm 0.16$ & - & - & - & - \\
\hline 30 & No change & $85.21 \pm 0.09$ & No change & $85.01 \pm 011$ & No change & $84.01 \pm 0.67$ \\
\hline 60 & No change & $85.071 \pm 0.09$ & No change & $84.99 \pm 1.2$ & No change & $83.88 \pm 0.23$ \\
\hline
\end{tabular}

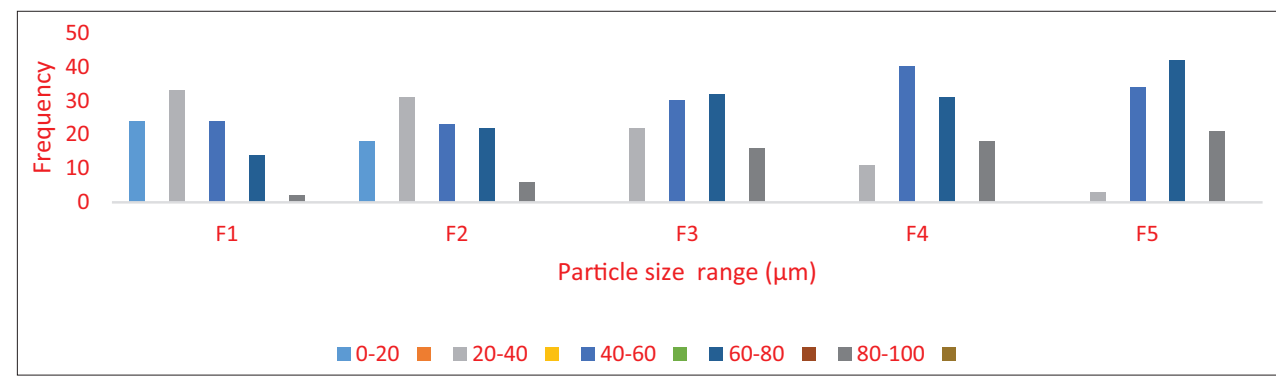

Fig. 4: Particle size distribution graph of F1-F5 by optical microscopy

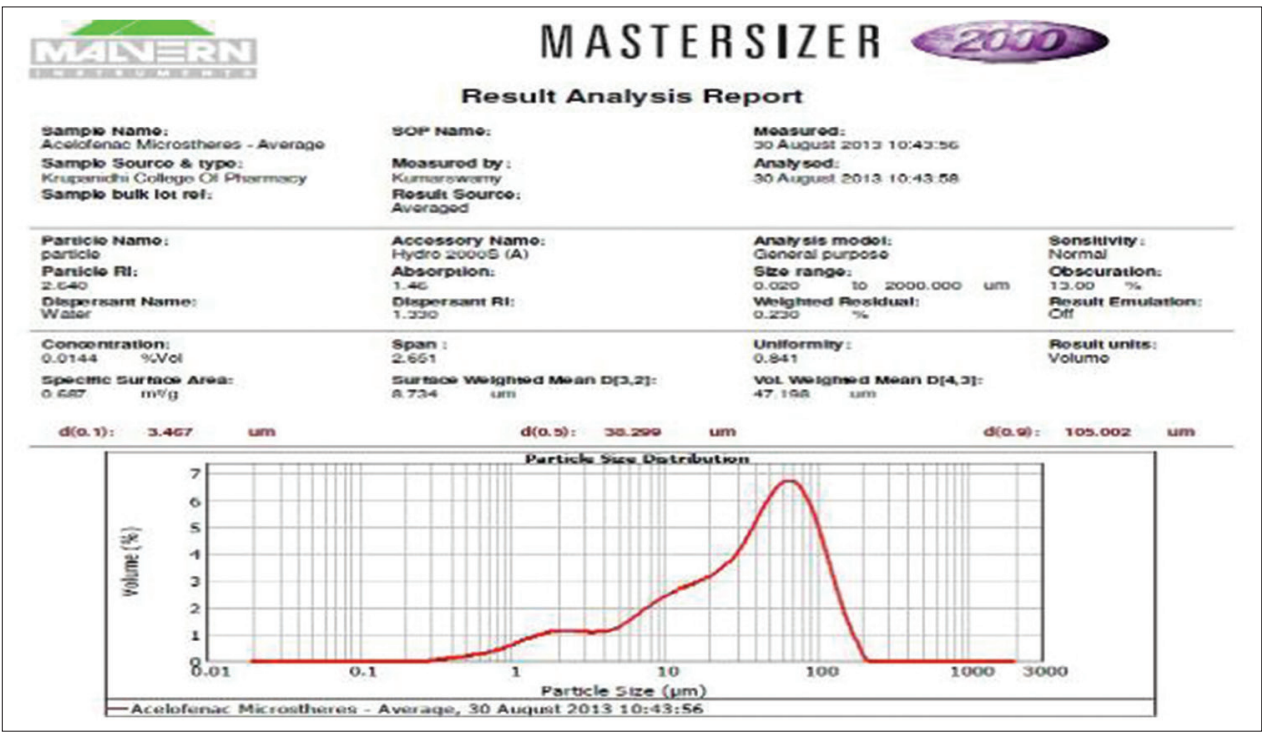

Fig. 5: Particle size distribution graph of F4 by zetasizer

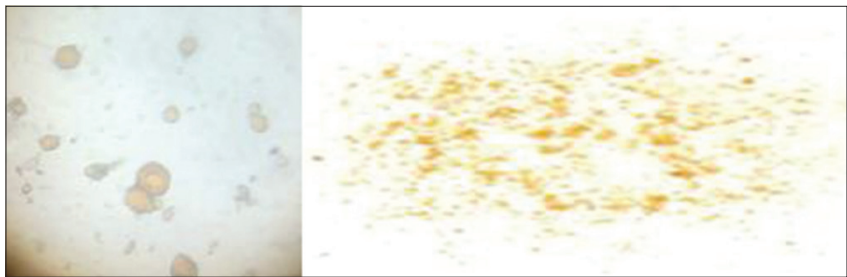

Fig. 6: Photograph of the microspheres

As given in the Table 2, the kinetics of the drug release was studied by fitting the release data to various kinetic models. It was seen that the release data was best fitted to Higuchi matrix model. Higuchi model is the kinetic model that describes the drug release from both semisolids and solid matrices. In this model the release data was plotted as cumulative percentage of drug release versus square root of time. The mechanism of drug release from the microspheres seems to follow an anomalous behavior which is the combination of Fickian and non Fickian transport mechanism. For anomalous release behavior, $\mathrm{n}$ vales are above $\geq 0.5$.

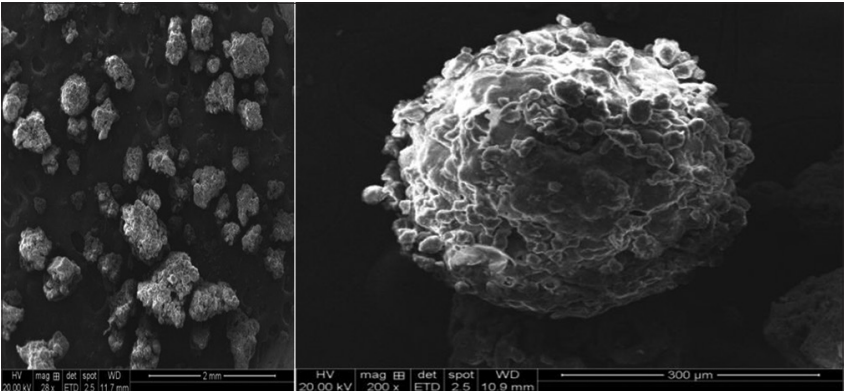

Fig. 7: SEM of the selected formula F4

The ex vivo permeation studies using excised porcine intestinal sample showed an advanced permeation profile of the drug from the microspheres to the neat sample of aceclofenac. (Fig. 9). It is reported that chitosan has good solubilizing properties and has a good permeation enhancing property across the biological membranes. So these properties might have added to the increased rate of permeation. 


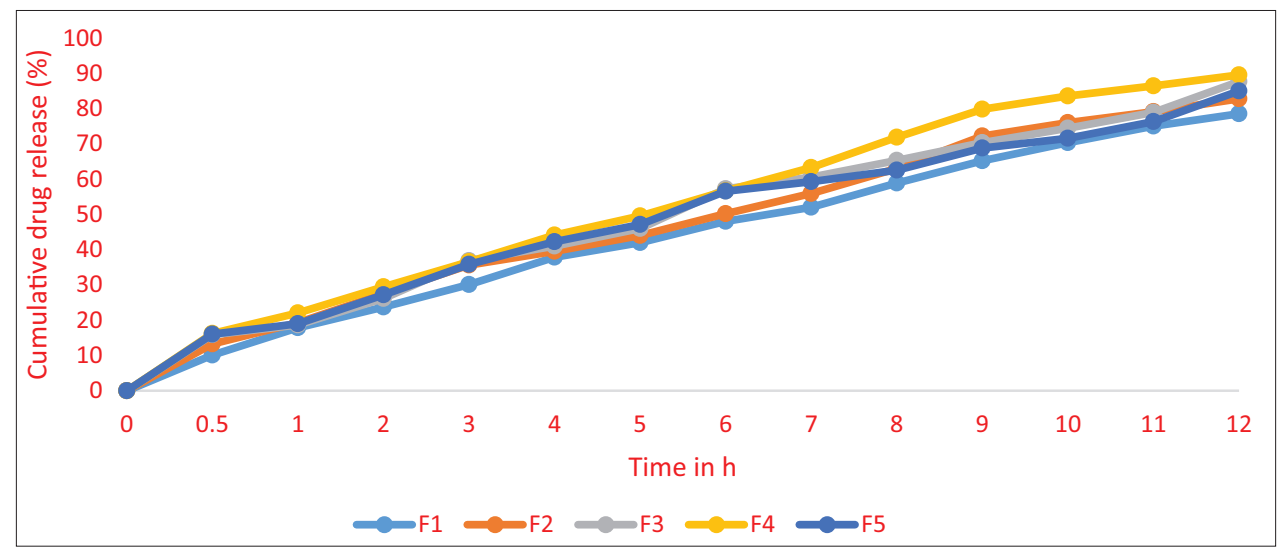

Fig. 8: In vitro release profile of aceclofenac microspheres

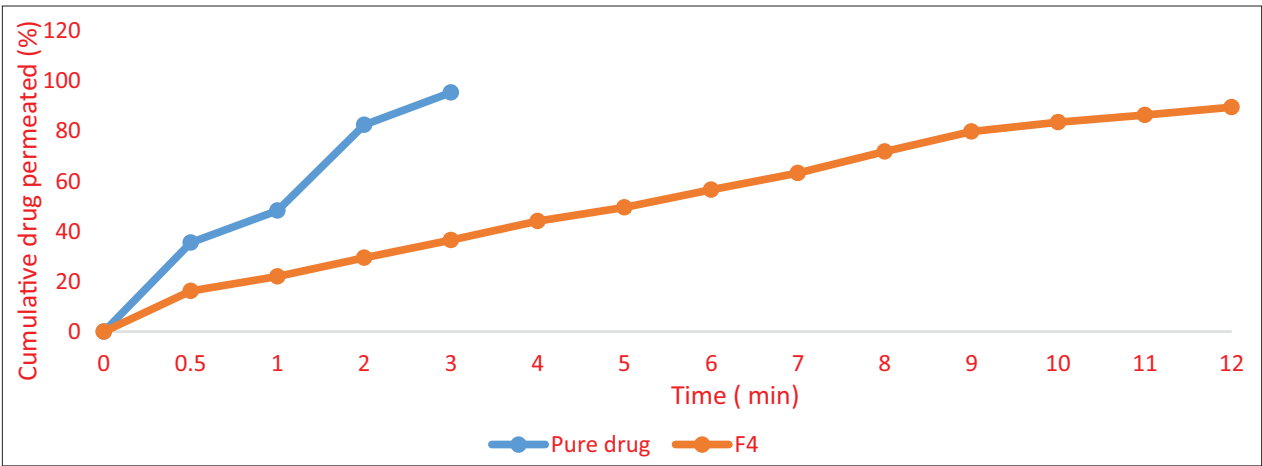

Fig. 9: Ex-vivo permeation study of the selected formula F4 vs Aceclofenac pure drug

\section{Stability studies}

Short term accelerated studies at $25^{\circ} \mathrm{C}, 30^{\circ} \mathrm{C}, 40^{\circ} \mathrm{C}$ of the selected formula (F4) indicates slight decrease in the drug entrapment efficiency as the temperature is increased. As given in the Table 3. However there were no changes in physical appearance observed.

\section{CONCLUSION}

The concept of formulating microspheres containing aceclofenac offers a suitable, practical approach to achieve a prolonged therapeutic effect by controlling the release of the medication over extended period of time. In present work, controlled microspheres of aceclofenac were prepared in order to minimize the side effects by controlling the release of the drug in the gastric environment. This was achieved successfully by emulsification cross-linking method using the different concentration of natural polymer chitosan. Microspheres were found to be spherical with slight uneven surface, which was confirmed by SEM. As the drug to polymer ratio was increased, the mean particle size of aceclofenac microspheres also increased with the range of $20 \mu \mathrm{m}$ to $100 \mu \mathrm{m}$. The microspheres exhibited good mucoadhesive retention properties on porcine mucosal tissue sample.

Therefore it can be concluded that microspheres of aceclofenac using chitosan polymer would be an excellent approach for gastric retention along with a controlled drug release.

\section{ACKNOWLEDGMENTS}

Author would like to thank the management, Krupanidhi College of Pharmacy Bangalore for providing facilities to conduct the experiments. They are thankful to Micro labs Bangalore for gift sample of aceclofenac and CIFL Cochin for chitosan gift sample.

\section{AUTHORS CONTRIBUTION}

The authors declare that the work is done by the authors named in the article; Ms. Saroja S.P. has carried out all the laboratory work,
Dr. Preethi Sudheer has done all ground work and preparation article and proof reading.

\section{CONFLICTS OF INTEREST}

The authors declare that there are no conflicts of interest regarding the publication of the paper.

\section{REFERENCES}

1. Ravi S, Peh KK, Darwis Y, Murthy B, Singh TR, Mallikarjun C. Development and characterization of polymeric microspheres for controlled release protein loaded drug delivery system. Ind J Pharm Sci 2008; 70 (3):303-09.

2. Carvalho I BruschiML, Evangelista RC,Gremio MPD. Mucoadhesive drug delivery systems. Braz. J. Pharm Sci. 2010; 46:1-17.

3. Chein YW. Novel drug delivery systems. $2^{\text {nd }}$ ed. New York: Marcell Dekker Inc; 1992.

4. Nappinnai M., Sivaneswari S. Formulation optimization and characterization of gastroretentive cefpodoxime proxetil mucoadhesive microspheres using $3^{2}$ factorial design. J Pharm Res 2013; 7:304-09.

5. Preethi S Anjana A. Mucoadhesive Polymers: A review. J Pharm Pharm Res. 2018; 17 (1):47-55

6. Martindale: The complete drug reference. $36^{\text {th }}$ ed. London, UK: The Pharmaceutical Press; 2009

7. Arul B, Kothai R, Sangameshwaran B, Jayakar B. Formulation and evaluation of chitosan microspheres containing Isoniazide. Ind J Pharm Sci 2003; 65:640-42.

8. Chirag N, Narendra C, Sandip P, Keyur A, Dhruti N. Design and characterization of bioadhesive microspheres prepared by double emulsion solvent evaporation method. Acta Pharm Sci 2009; $51: 261-70$

9. Anil KA, Willem FS, Carmen L. Ionotropic crosslinked chitosan microspheres for controlled release of Ampicillin. Int J Pharm Sci 2006;312:166-73.

10. Chowdary KPR, Sriramamurthy.A. Microencapsulation in pharmacy. Ind Drugs 1992; 259:389-402.

11. Muthshamy K, Shibi KP. Preparation and evalution of albumin-chitosan 
microspheres containing Theophylline. Ind J Pharm Sci 2010; 50:117-241.

12. Dada Khalandar KS, Sudhakar Y, Jayaveera.KN. Chitosan based nasal microspheres of sumatriptan: Formulation and in-vitro evaluation. Res J Pharm Bio Chem Sci 2011; 2(3):489-98

13. Sanju D, Anil KS, Vivek R, Sinha VR. Evaluation of mucoadhesive properties of chitosan microspheres prepared by different methods. AAPS Pharm Sci Tech 2004; 5:1-7.

14. Murali Mohan Babu GV, Himasankar K, Narayan Churuvu PS, Ramana Murthy KV. Controlled release of diclofenac sodium by gum karayachitosan complex coacervate: In vivo evaluation. Ind J Pharm Sci 2001;
63:408-12.

15. Monica RPR, Snehal R.G, Prachi MS. Synthesis and characterization of a novel mucoadhesive derivative of Psyllium seed polysaccharide. Int J Pharm Pharm Sci 2017; 9(6):166-75.

16. Raviteja G., Narayana Reddy KVVS, Mahendran B, Meghana GGN, Ganesh K. A mucoadhesive gastroretentive dosage form for Valacyclovir Int J Pharm Pharm Sci, 2014; 6(9):422-427.

17. Yueling Z, Wei W, Piping LV, Lianyan W, Guanghui M. Preparation and evaluation of alginate-chitosan microspheres for oral delivery of insulin. Eur J Pharm Biopharm 2011; 77:11-19. 